\title{
National Workshop on Asthma and the Environment
}

\author{
TOM WOOD MD MSC FRCPC, PIERRE ERNST MD MSC FRCPC \\ University of Western Ontario, London, Ontario, McGill University, Montreal, Quebec
}

\section{T WOOD, P ERNST. National workshop on asthma and the environment. Can Respir J 1994;1(1):61-65.}

A national workshop on asthma and the environment was held October 23 and 24, 1992, in Montreal, Quebec. Twenty-nine speakers presented datal on asthma from at Canadian perspective. A number of recommendations were produced which will influence future asthma research and management in Canada.

Key Words: Aeroallergens, Air qualit, A.rhma, Environment

\section{Atelier national sur l'asthme et l'environnement}

Un atelier national sur l'asthme et l'environnement s'est déroulé du 23 au 24 octobre à Montréal (Québec). Vingtncuf conférenciers ont présenté des données d'un point de vue canadien. Un certain nombre de recommandations formulées à cette occasion orienteront la recherche future et le traitement en matière d'asthme au Canada.

\begin{abstract}
$\mathrm{I}_{\mathrm{H}}^{\mathrm{N}}$ N 1991 THE CANADIAN LUNG ASSOCLATION'S ENVIRONMENTAL. Health Committee (co-chaired by David Pengelly, Hamilton, and Beth Savan, Toronto) suggested a workshop on asthma and the environment, and a planning committee (chaired by Pierre Ernst, Montreal) was set up.

The INSPIRAPLEX Respiratory Centres of Excellence agreed to act as host, and sponsorship by the Laboratory Centre for Disease Control, The Lung Association, Canadian Thoracic Society, and the Canadian Society of Allergy and Clinical Immunology was arranged. Support was provided by the National Health Research and Development Program of Health and Welfare Canadit and the Medical Research Council of Canada. The workshop, which canc to be called the National Workshop on Asthmat and the Environment (NWAE) took place on Octoher 23 and 24, 1992, in Montreal, Quebec.
\end{abstract}

The Environmental Health Committee hoped that NWAE would act as a forum for discussion, so participants were invited from academia, government, and nongovernmental organizations across the country, and arrangements were made which would promote an exchange of ideas. One-third of each speaker's time was reserved for discussion, and all sessions, meals, and discussion groups took place in the same area of the hotel. Almost all of the participants were Canadian, but Ann Woolcock of Australia, who was in the country as Simms Travelling Professor of the Royal College of Physicians, was invited to attend.

Sessions were co-chaired by Margaret Becklake from Montreal, and Moira Chan-Yeung from Vancouver. Dr Chan-Yeung stated the workshop's aims:

- to identify and catalogue ongoing Canadian research on asthma and its relation to the environment;

- to propose and improve study designs as weli als standardize heatth and environmental measures to promote comparability of results across Canada and avoid duplication of efforts; and

- to recommend an agenda for research and action for reducing asthma morbidity in Canada in the next five years.

\section{ASTHMA: BACKGROUND}

Dr Chan-Yeung described asthma as a multifactorial discase. She felt the most important determinants are genetic predisposition and exposures in the enviromment, both indoor and outdoor. She introduced the concept of "inducers' of asthma and "triggers' of asthmatic attacks. Inducers are 
agents that may cause asthma in a previously healthy subject. Induction of asthma is associated with an increase in bronchial hyperresponsiveness, and occurs with allergens such als house dust mites, pollens, fungi and industrial exposures such as isocyanates. Triggers of asthma are agents that provoke attacks of asthma in a known asthmatic, and usually not associated with an increase in bronchial hyperresponsiveness. Stimuli that can trigger attacks include exercise, cold air and exposure to air pollutants.

Dr Chan-Yeung stated that genetic predisposition also plays an important part in asthma; little is known about genetic markers, and there is more understanding of the genetic aspects of atopy. Sensitization to common allergens occurs in the first two years of life, and studies of the interaction between atopic predisposition and environmental exposure during this window of life are likely to add to our understanding of asthmal.

Sverre Vedal, also from Vancouver, reviewed asthma and air pollution episodes. Outbreaks of asthma in Barcelona, Spain, were recently shown to be due to airborne soybean dust from the unloading of soybean in the city harbour. Other outbreaks, although not as clearly attributed to organic dusts, have been described in New Orleans, Louisiana, in Minneapolis, Minnesotia, and in Yokohama, Japan.

In the past, severe air pollution episodes have been accompanied by dramatic increases in respiratory illness and death, with most deaths occurring in people with chronic obstructive lung disease. The best known episode occurred during the smog of 1952 in London, England.

Exposure to aeroallergens such as pollen and pet allergens can clearly cause exacerbations in asthmatics, but it is less clearly appreciated that exposure to house dust mites and fungal spores can also lead to exacerbations.

Most of the information on the adverse health effects of air pollution involve suspended particles, sulphur dioxide, nitrogen dioxide or ozone. Ambient sulphur dioxide is largely produced by the combustion of fossil fuels that contain sulphur impurities; ground level ozone is formed by the interaction of nitrogen oxide (largely produced by automobiles), hydrociarbons and sunlight. The combination of ozone with other contaminants may be more harmful than exposure to ozone alone. The concentrations of sulphur dioxide and ozone are generally low indoors, with the exception of homes with kerosene heaters where high sulphur dioxide concentrations have been measured. Indoor nitrogen dioxide from the combustion of natural gas in gas stoves appears to cause more respiratory symptoms in children, but has not been shown to affect asthmatics more adversely.

\section{ASTHMA AND THE INDOOR ENVIRONMENT}

Dr Woolcock presented data on the relation of house dust nites and asthma, a theme which surfaced repeatedly at the workshop. In a study of 807 children aged eight to II years in a humid rural area of Australia, where house dust mite allergen levels were so high they set records, $27 \%$ of the children wheezed, $19 \%$ had airway hyperreactivity and $11 \%$ had both, meeting Dr Woolcock's criteria for current asthma.
In another, less humid, area the prevalence of asthma in children was $8.7 \%$. Risk factors for asthma were allergy, parental asthma and a respiratory illness under the age of two years; sex, age, and parental smoking were not important risks, once these factors had been accounted for. Among atopic children, allergy to house dust mites was the greatest risk factor, followed by allergy to cats and Alternaria spores.

Claire Infante-Rivard of Montreal studied the indoor environment and asthma in three- and four-year-old children who presented to emergency rooms. The predictors of asthnia were familial susceptibility, the mother's (or babysitter's) hoavy smoking, a humidifier in the child's room, and all electric heating system in the house. Twenty per cent of the children were asked to wear a nitrogen dioxide badge for $24 \mathrm{~h}$, and there was a dose-response relationship between asthma and nitrogen dioxide levels; in houses built after 1970) this risk increased.

In a second Montreal study of six- to 12-year-old school children by Pierre Ernst, however, there was no strong association between asthma and crowding, damp damage, cooking fucls or environmental tobacco smoke. And in a third study done in Port Alberni, British Columbia, hy Sverre Vedal, peak expiratory flow rate (PEFR) variability was increased in children with high house dust mite exposure, but asthma was not associated with a cat in the home.

Alexander Ferguson, Vancouver, recommended controlling house dust mites by covering mattresses with zippered plastic covers, removing carpets, washing bedding in water at $55^{\circ} \mathrm{C}$, and lowering the indoor humidity to $50 \%$. Several acaracides are effective but they require frequent application and although they kill mites, they do not remove the allergenic proteins. Vacuum cleaning and carpet shampooing are ineffective, and increasing ventilation in the home works only if outside humidity is low.

Paul Comptois of Montreal reported that indoor factors influencing asthma include natural materials in the bedroom (especially cotton mattresses), wood walls and floors, and molds, chiefly Aspergillus and Penicillium spores. The smaller a spore is, the more likely it is to become airborne and affect health. Plants do not have an impact, nor does humidity unless it is related to a home nebulizer.

The study of allergy and exposure to molds has lagged behind that of house dust mite exposure, according to Zave Chad, Montreal. Dr Chad called molds "the forgotten ateroallergens in asthma", and felt this was because they are so hard to quantify. Cladosporium, Alternaria, Penicillium and Aspergillus are the most commonly found spores, and the last two are the most common indoors. Fungal volatiles are lirequently detected as moldy smells, but there are no tata available on their long term effects.

Asthma and nonallergic exposure in indoor air was discussed by Dennis Bowie from Halifax, Nova Scotia. A number of combustion products, volatile organic products, bioaerosols, particulates and irritant gases are found in indoor air. Their concentrations are altered by temperature, humidity, ventilation, and the use of a ventilating system (but not filters); the effect of combined exposures is not known, 
although these agents are incriminated in 'sick building syndrome'. An aura of hysteria surrounds the subject and objective evidence of obstructive airway disease is hard to find.

Richard Menzies surveyed by questionnaire the role of aeroallergens in producing respiratory symptoms in full-time workers in six office buildings in Montreal. Although over half the workers who had symptoms said they improved when they stayed away from work, there was no significant difference between cases and controls in environmental conditions and the level of aeroallergens. As in similar studies, the office environment was measured on only a few occasions and significant exposures could have been missed.

\section{ASTHMA AND THE OUTDOOR ENVIRONMENT}

Several speakers discussed the relation of community air pollution and asthma admissions. Analysis of data obtained in Ontario between 1983 and 1988 by Richard Burnetı, Ottawa, showed a peak of asthma admissions in September, with acute bronchitis, pnemmonia and chronic respiratory disease peaking in January in relation to the annual influenza epidemic. Respiratory admission rates from May to August correlated with sulphur dioxide levels measured on the day of admission and up to three days before. Burnett found a similar pattern with ozone, except that there is little effect on the day of admission, and ozone and sulphur dioxide seem to have a synergistic effect.

In Montreal, Ralph Delfino found admissions from 1983 to 1988 to 31 hospitals for all respiratory illnesses, with and without asthma, were significantly associated with levels of sulphate, particles less than $10 \mu \mathrm{m}$ in size, and total suspended particles, despite the fact that levels of these materials rarely exceeded Canadian standards.

A study of asthma at the Winnipeg Children's Hospital in 1991, by Jure Manfreda, did not show correlations between tree and grass pollens, emergency room visits and asthma admissions, but ragweed counts did correlate with emergency room visits and less well with admissions. Other Manitoba data collected between 1979 and 1989 showed no association between asthma and sulphur dioxide, nitrogen dioxide or ozone, but there was a significant relationship between asthma and total suspended particles.

In the Ottawa-Carleton region a fall peak in asthma admissions follows the peak of the ragweed and mold seasons by a few weeks. This suggests that these allergens may induce late-phase inflamatory responses and increase bronchial reactivity to set the stage for viruses, pollutants or other allergens to act. These data were reported by Michel Drouin, Ottawa.

The relation of asthma and the outdoor environment is still far from clear. The use of general practitioners' and specialists' services by asthmatics, reported by David Pengelly, Hamilton, was associated with increased sulphur dioxide levels and coefficient of haze (a measure of fine particle concentration), although not with increases in ozone or other pollutants.

In an exhaustive examination of environmental and hospital data from Saint John, New Brunswick, by Robert
Beveridge, no relationship between environmental pollution and emergency visits for asthma was found, although there was a weak correlation between nitrogen dioxide and ozone and respiratory symptoms of cough, congestion, difficulty breathing, and shortness of breath. Dr Beveridge presented the workshop's most dramatic image, that of a cloud of ozone moving up the eastern seaboard of the United States, arriving at the Maine-New Brunswick border at midnight, and reaching the St John River Valley at about 02:30.

Pierre Lajoie, Quebec City, reported a significant negative association between the number of emergency room visits per day and temperature, and weak associations between visits and ozone and nitrogen dioxide levels. Dr Lajoie mentioned the impressive facts that $12 \%$ of 3005 asthmatics visited the emergency room three or more times, accounting for $36 \%$ of the visits, and that almost $25 \%$ took no drugs, even though they repeatedly visited the emergency room

Allan Becker, Winnipeg, investigated both outdoor and indoor allergens on the prairies, and found that tree and grass pollens did not correlate with emergency room visits or hospital admissions, but ragweed correlated strongly with visits, and significantly with admissions. No correlation was found between visits and total mold counts, and although the seven-day cumulative valuc for Alternuriu correlated with emergency room visits, there was no admissions peak. Using a multiple regression analysis, both emergency room visits and admissions showed a strong association with ragweed and Cladosporum spores in the late summer and early fall.

Susan Tarlo, Toronto, reported on the factors associated with low level ozone and airway disease. The most important is the dose of ozone delivered to the airways, which depends on the ambient concentration, the expired minute volume $\left(F E V_{1}\right)$, and the duration of exposure. The current Canadian ambient air quality standard for ozone is 0.08 parts per million (ppm) for $1 \mathrm{~h}$, but levels in some Canadian cities during the summer reach $0.16 \mathrm{ppm}$ or more.

The interaction of ozone and aeroallergens was investigated by Noe Zamel, Toronto. He found no significant differences in FEV, after exposure to ozone but when allergen was prececded by ozone, there was an increase in bronchial reactivity.

The last speaker of the session on the outdoor environment was Ambikaipakan Senthiselvan, Saskatoon. In his investigations of pesticide-induced asthma in male Saskatchewan farmers, he found a significant association between asthma and exposure to cholinesterase-inhibiting insecticides.

\section{ASTHMA IN CANADA TODAY}

A problem for those who teach or speak in public is that simple, up-to-date numbers that the public can easily understand are difficult to obtain. Kathryn Wilkins, an epidemiologist with Health Canada's Laboratory Centre for Disease Control who edits Chronic Diseases in Canada, reported a number of useful figures. An average of 11 childiren under 15 years of age die in Canada of asthma cvery year. Although from age 15 to 34 the death rate is twice that of the younger age group, the death rate has not changed since the 1980s. 
However, hospitalizations for asthma increased by $40 \%$ between 1980 and 1988, and the rate of admission was five times higher for people under 15 years than for those aged 15 to 34 . The rate of first-ever medical consultations for asthma doubled between 1979 and 1990, suggesting that the incidence of the disease in Canada has increased.

Robert Diles, also from Ottawa, reviewed the prevalence of asthma in Canada. Using a questionnaire, he surveyed 17,962 families of children five to eight years old and found that $4.7 \%$ had physician-diagnosed asthma, $13 \%$ had wheezing and $6 \%$ had persistent cough. Asthma prevalence was highest in the Maritimes (7.4\%) and lowest in British Colonbia $(3.3 \%)$ and Quebec $(3.4 \%)$. This regional variation corresponded to distances between provincial hospitals, and was not explained by child's age and sex, respondent's age, passive smoking, gas or wood stoves, home mold/dampness, maximal parental education, pets, or hobbies in the home.

Lamont Sweet, Charlottetown, discussed a study which was done on asthma deaths in Prince Edward Island because, except for the year 1980, asthma deaths in that province from 1979 to 1988 appeared to be three times the national average. There were 34 coded asthma deaths in the years 1984 to 1988, and their death certificates, hospital charts and autopsy reports were reviewed. Using established criteria for asthma death, only three cases under fïve years and four cases over 49 years were considered valid diagnoses of asthma. A total of 22 cases $(65 \%)$ were judged to be invalid, all over 50 years of age; the records had been coded incorrectly due to physician misunderstanding, or to an international coding rule which gave precedence to asthma deaths over other causes appcaring on the death certificate. Dr Sweet also reviewed Prince Edward Island's asthma hospitalization study, in which a $10 \%$ sample of 4230 hospital charts were reviewed; the valid adnission rate was found to be $69 \%$. Patients from rural areas were under-represented, and the diagnosis of asthma was found to be most accurate $(88 \%)$ in the $10-10$ 39-year-old age group.

\section{NEW TECHNIQUES FOR THE INVESTIGATION OF ASTHMA}

Irving Broder,Toronto, discussed the investigation of air pollution, commenting that after 1975 research used detailed examination of exposures in susceptible populations, with searches for dose/response relationships. Since a biological dose is rarely available, data from government measurements at fixed outdoor sites can be used, despite the fact that they are imprecise and do not represent what happens indoors. Exposure models are currently being developed, which will provide the most precise estimate while exposing the subject to the least risk, and at a low cost.

Frances Silverman. Toronto, described three approaches to research on asthma. Animal studies provide evidence of pollution-induced damage, but it is difficult to extrapolate the results to humans, and experiments are often done at higher levels than humans encounter. Epidemiological studies allow examination of complex outcomes, but because of the complexity of air pollution mixtures it is difficult to establish cause/effect and dose/response relationships. The third technique is the 'clinical study', in which human subjects are exposed to low levels of pollutants under controlled laboratory conditions. Dr Silverman echoed Dr Broder's contention that experimental human exposure in the laboratory allows for control of variables, but the number of subjects is limited, it is difficult to duplicate environmental conditions, and ethical considerations impose constraints. Accidents with high concentrations (such as Bhopal) can also be examined, allowing the study of conditions which cannot be used experimentally for ethical reasons.

New techniques which could be used in asthma investigation in Canada were discussed. Mark Raizenne, Ottawa, described a 'spiromodem', an instrument which will allow subjects to record spirometry independently at home and download it to a computer at another location at an appropriate time.

Another research tool for population studies is PEFR variability, discussed by Robert Cowie, Calgary. Dr Cowie stated that questionnaire responses are not specific for asthma and they may be insensitive because they depend on community awareness. He felt that the PEFR, although it might not detect all the asthmatics in a population, could easily give an index of prevalence.

Finally, James Day of Kingston described an environmental chamber that he and R Clark developed which cxposes individuals to environmental materials and allergens in a controlled fashion and allows the careful evaluation of resulting respiratory tract disease.

\section{PROPOSED RESEARCH}

Plans for four research projects were described and discussed. The first, by Suzanne Tough, Edmonton, will study all patients aged five to 50 years dying of asthma in the prairic provinces from November 1, 1992 until November 1, 1995. Information about the patients' demographics, lifestyle, medication, occupation and their acute event will be sought. This will be compared with data from population controls matched for age, gender, demographic variables and characteristics of disease. A second control group will consist of matched cases of asthma treated in an emergency within two weeks of the fatal case. It is anticipated that 70 fatal cases of asthma will be collected, and lead to a clearer understanding of the factors involved in high risk cases.

The Laboratory Centre for Disease Control, Health Canada, will participate in the prairie provinces project, according to Dr Felix Li, Ottawa, and will also incorporate an asthma questionnaire into the 1994 and subsequent Canada Health Surveys.

Patrick Hessel, Edmonton, described plans for a third study which will investigate conditions in four communities in Alberta where citizens have expressed concerns about the effects of pollution from local petrochemical or forest product industries on their lung health.

A fourth project was described by Donald F Stark, Vancouver. The Canadian Society of Allergy and Clinical Immunofogy plans to estimate the prevalence of atopic disease with 
a study of 2000 Canadian students aged 17 to 25 years who have lived for three or more years in the same place.

\section{RECOMMENDATIONS OF THE WORKSHOP}

After a great deal of discussion, 30 recommendations were made. The first of these, as might be expected from a meeting where the value of communication was so amply demonstrated, was that more workshops should be held, having a similar format, to discuss study design, maximize resource use, and avoid duplication of effort. The rest of the recommendations, although they covered many specific issues which the participants felt should be specifically mentioned, could be collected into four main themes.

The first was the importance of establishing standardized instruments for the collection of data, with recommendations regarding the use of a standardized asthma questionnaire, standardized skin testing methods, and the use of sentinel hospitals and physicians to provide quality data in an organized and consistent way.

The extent and the depth of the discussion made it clear to all participants that much more needs to be known about asthma, both in terms of aeroallergens and the environment in and out of doors. This leads to another group of recommendations, for the establishment of nationwide aeroallergen and air pollution monitoring networks, and for the investigation of the interaction of the many factors involved.

Another common theme in the recommendations was that methods for the control of factors causing asthma need to be sought. This could begin with the setting of reasonable air pollution standards.

The final group of recommendations concerned the dissemination of information on the management of the two causes of asthma about which much is already known: the abolition of cigarette smoking, and the control of the house dust mite. 


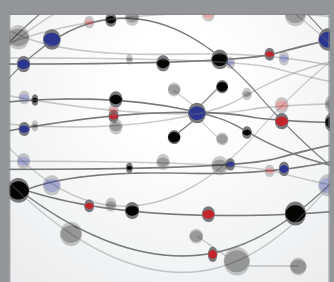

The Scientific World Journal
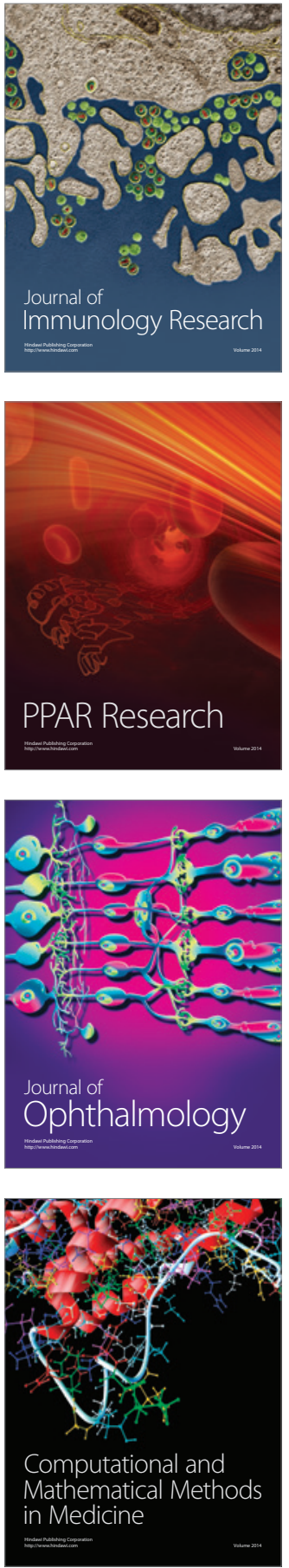

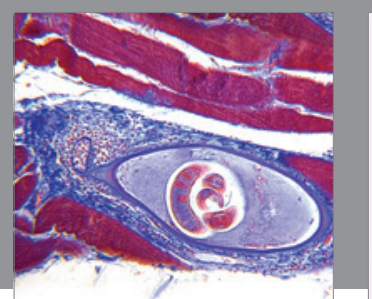

Gastroenterology Research and Practice

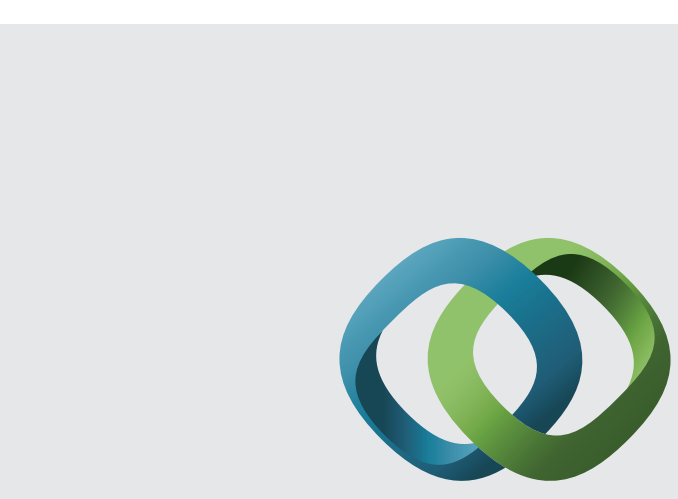

\section{Hindawi}

Submit your manuscripts at

http://www.hindawi.com
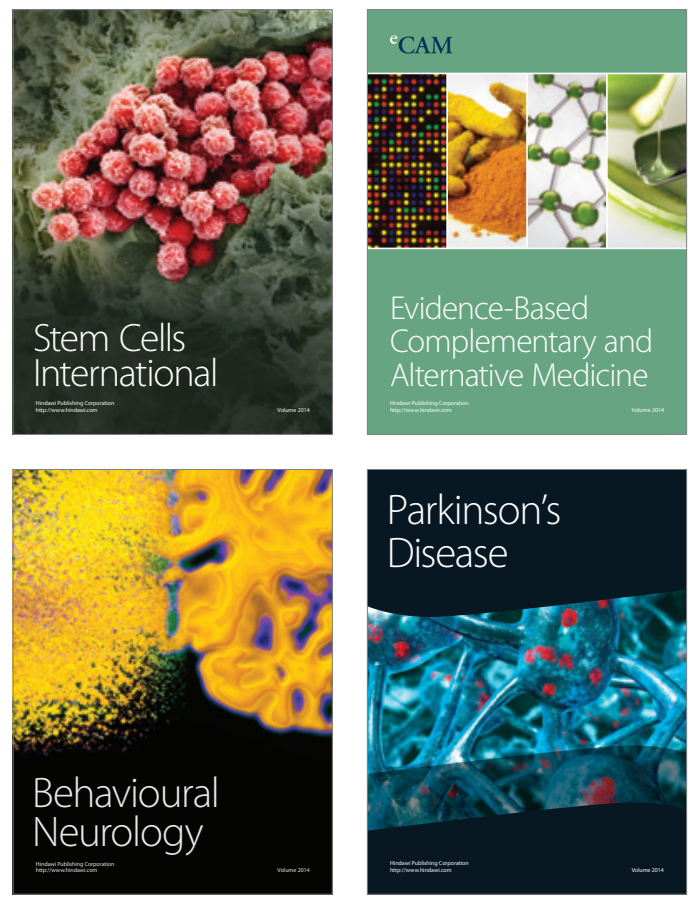
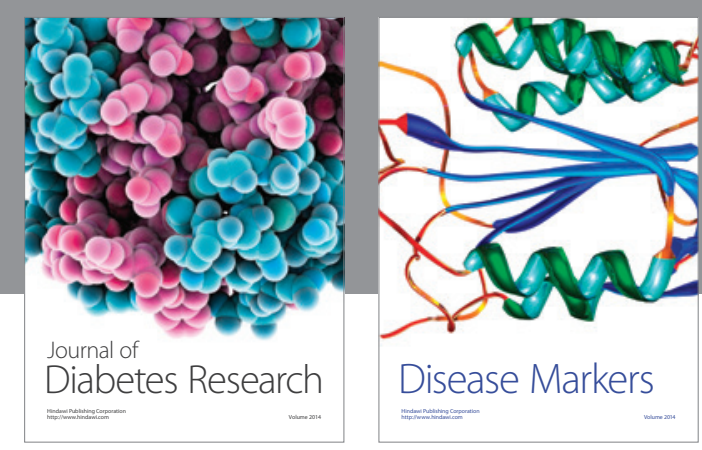

Disease Markers
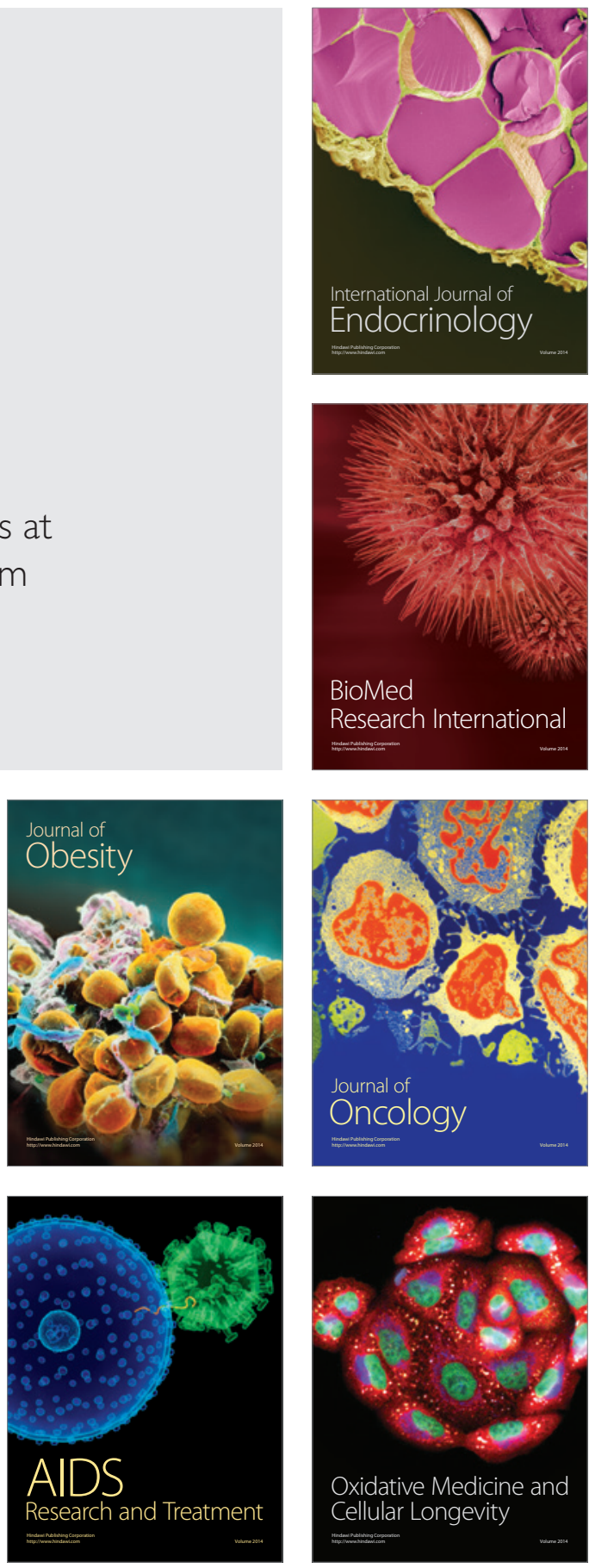